Panorama económico, político y sanitario de América Latina y el Caribe al comienzo de la pandemia del COVID-19

Luis Eduardo Peñafiel Chang 


\section{Panorama económico, político y sanitario de América Latina y el Caribe al comienzo de la pandemia del COVID-19}

Resumen: Con este articulo se busca reducir la dimensionalidad de un grupo de variables económicas, sanitarias, sociales y politicas de paises de América Latina y el Caribe mediante la aplicación de componentes principales (CP) y clúster, para adquirir una mejor percepción respecto a las condiciones con las que contó la región para afrontar el primer momento de la pandemia del COVID-19 con corte al 10 de abril de 2020. Entre los principales resultados se encuentra que los países que conservan mejores indicadores sociales, de estabilidad política y corrupción no solo poseen superiores infraestructuras sanitarias, sino que además fueron los que mejor gestionaron la primera fase de la pandemia. Sin embargo, si las buenas condiciones no son combinadas con estrategias de mitigación, el virus tiende a una mayor propagación. Por otra parte, se distinguen también características generales en América Latina y el Caribe, como poca inversión en salud; baja cantidad de pruebas de COVID-19 y limitada maniobra financiera. En sintesis, el panorama económico, politico y social de la región muestra los grandes retos que persistirán durante y después de la pandemia.

Palabras clave: instituciones políticas, análisis multivariado, relaciones económicas internacionales, politica de la salud, COVID-19.

Clasificación JEL: C45, E65, H51, I18.

\section{Economic, Political and Health Panorama of Latin America and the Caribbean at the Beginning of The COVID-19 Pandemic}

Abstract: This article seeks to reduce the dimensionality of a group of economic, health, social and political variables of Latin American and Caribbean countries through the application of principal components (PC) and cluster, to acquire a betterperception regarding the conditions under which counted the region to face the first moment of the COVID-19 pandemic with cut-off to April 10, 2020. Among the main results is that the countries that have better social, political stability and corruption indicators not only have superior health infrastructures, but they were also the ones that best managed the first phase of the pandemic. However, if good conditions are not combined with mitigation strategies, the virus tends to spread further. On the other hand, there are also typical characteristics in Latin America and the Caribbean, such as little investment in health; low amount of COVID-19 testing and limited financial maneuvering. In summary, the economic, political, and social panorama of the region shows the great challenges that will persist during and after the pandemic.

Keywords: political institutions, multivariate analysis, international economic relations, health policy, COVID-19.

\section{(cc) BY-NC-SA}

Este artículo y sus anexos se distribuyen por la revista Lecturas de Economía bajo los términos de la Licencia Creative Commons Atribución-NoComercial-CompartirIgual 4.0. https://creativecommons.org/licenses/by-nc-sa/4.0/ 


\section{Panorama économique, politique et sanitaire d'Amérique latine et des Caraïbes au début de la pandémie de COVID-19}

Résumé: Cet article propose une analyse concernant la réduction de la dimensionnalité d'un groupe de variables économiques, sanitaires, sociales et politiques de la région d'Amérique latine et des Caraïbes, à travers l'application de la méthode de composantes principales (PC) et de cluster. Cette démarche sert à avoir une meilleure perception des conditions qui avait la région avant le 10 avril 2020, c'est-à-dire, juste avant l'arrivée de la pandémie de COVID-19. Parmi les principaux résultats, nous montrons que les pays qui avaient de meilleurs indicateurs de stabilité sociale, politique et de faible corruption ont, non seulement des infrastructures de santé supérieures, mais ils ont été aussi ceux qui ont le mieux géré la première phase de la pandémie. Cependant, si les bonnes conditions ne sont pas combinées à des stratégies d'atténuation, le virus a tendance à se propager davantage. Nous montrons également quelques caractéristiques générales d'Amérique latine et les Caraïbes à ce sujet, telles que le moindre niveau d'investissements dans la santé, la faible quantité de tests COVID-19 réalisés et le manque de stratégies financières innovatrices. En résumé, le panorama économique, politique et social de la région montre les grands défis qui persisteront pendant et après la pandémie.

Mots clés: Institutions politiques, analyse multivariée, relations économiques internationales, politique de santé, COVID-19.

\section{Cómo citar / How to cite this item:}

Peñafiel Chang L. E. (2021). Panorama económico, político y sanitario de América Latina y el Caribe al comienzo de la pandemia del COVID-19. Lecturas de Economía, (95), 11-44. https://doi.org/10.17533/udea.le.n95a344608 


\title{
Panorama económico, político y sanitario de América Latina y el Caribe al comienzo de la pandemia del COVID-19
}

\author{
Luis Eduardo Peñafiel Chang $\oplus^{a}$
}

-Introducción. -I. Situación económica y social de América Latina y el Caribe. -II. Metodología. -III. Resultados. -Conclusiones. -Anexos. -Referencias.

Primera versión recibida el 30 de noviembre de 2020; versión final aceptada el 19 de mayo de 2021

\section{Introducción}

América Latina y el Caribe junto con el resto del mundo vive - por un lado- una crisis sanitaria, humana y económica sin precedentes y por otro- una lucha por contener la propagación de la enfermedad de coronavirus (COVID-19) y reducir al mínimo las pérdidas de vidas (Peters, 2020). Los esfuerzos por contener el virus han dado lugar al cierre de las economías y cuarentenas más o menos severas, las cuales son medidas comparables a las de situaciones de guerra (Sanders, 2020; Peñafiel, 2020). Aunque no se sabe con exactitud cuánto durará la crisis ni la forma que podría tener la recuperación, lo cierto es que se ha dado un cambio completo en las perspectivas económicas y debate sobre políticas. La Figura 1 muestra el comportamiento del COVID-19 en Latinoamérica.

Esta crisis es un gran desafío para América Latina y el Caribe, dado que enfrenta la pandemia desde una posición más débil que la del resto del mundo (Lafuente, 2020). El propósito de este artículo consiste — por una parteen determinar las condiciones iniciales de la región para enfrentar la primera fase de pandemia y — por otra - cotejar si estas condiciones, sumado a las estrategias de mitigación, fueron eficaces para contrarrestar la propagación inicial del virus. Para ello, se propone analizar variables económicas, políticas, sociales y sanitarias mediante un análisis multivariado. En este sentido, este

a Luis Eduardo Peñafiel Chang: doctorando en la Pontificia Universidad Católica Argentina, Argentina. Dirección electrónica: lueduardo@uca.edu.ar https://orcid.org/0000-0002-5571-3978 
Peñafiel Chang: Panorama económico, político y sanitario de América Latina y el Caribe...

Figura 1. El coronavirus en América Latina

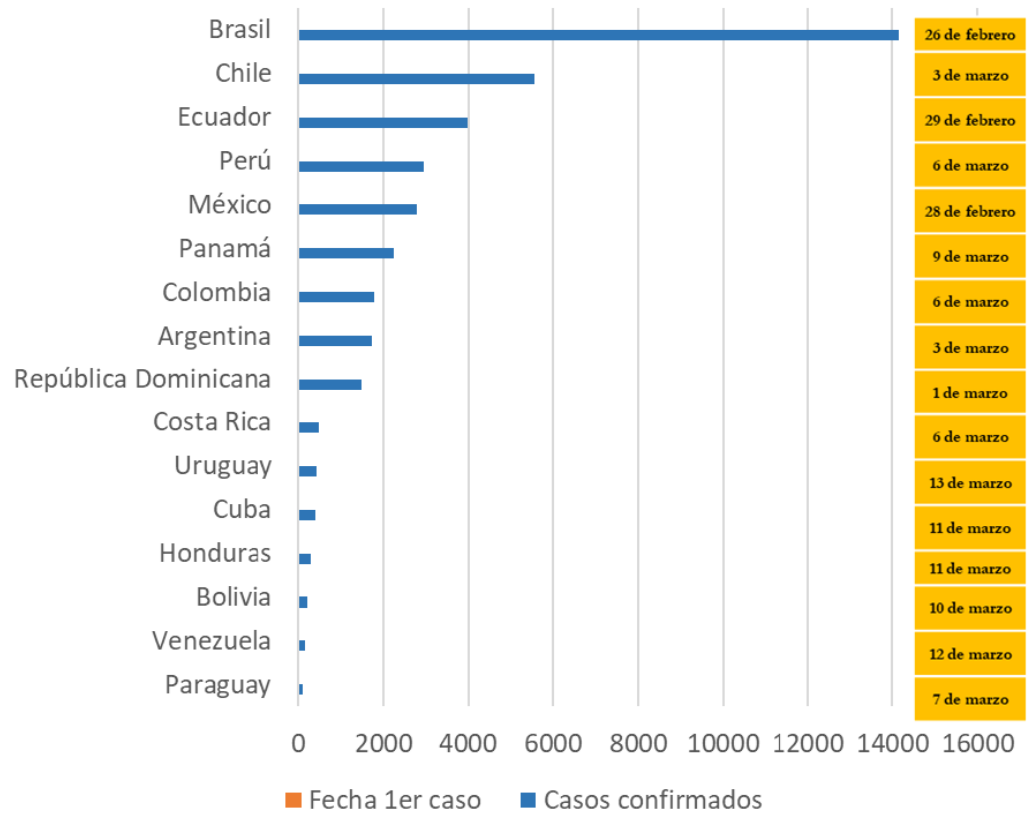

Nota: al 10 de abril de 2020.

Fuente: Centro de Ciencia e Ingeniería de Sistemas (CSSE, por sus siglas en inglés) de la Universidad Johns Hopkins (s. f.).

artículo adopta una perspectiva regional y consta de cuatro apartados: el primero ofrece un compendio de la situación económica y social de América Latina y el Caribe en el inicio de la pandemia, a continuación, se presenta los lineamientos metodológicos, posteriormente en el siguiente apartado se presentan los principales resultados y por último se reúnen las principales conclusiones.

\section{Situación económica y social de América Latina y el Caribe}

La pandemia del COVID-19 impactó América Latina y el Caribe en un momento de debilidad de su economía y de vulnerabilidad macroeconómica (CEPAL, 2019b; OIT, 2019; Maldonado et al, 2018) y a medida que la 
pandemia se propaga en la región, su caracterización como crisis sanitaria, económica y social es cada vez más evidente.

Los canales de transmisión de la crisis de COVID-19 en la región vienen dados por la reducción del comercio internacional, caída de los precios de los productos primarios, intensificación de la aversión al riesgo y el empeoramiento de las condiciones financieras mundiales, a todo esto, se suma una caída en la demanda de los servicios turísticos y la reducción de las remesas (CEPAL, 2020a) .

$\mathrm{Al}$ respecto, sus ya muy endeudadas economías dificultan la maniobra financiera para hacer frente a la velocidad de evolución de la pandemia y, según la Comisión Económica para América Latina y el Caribe —CEPALy el Grupo del Banco Mundial —WBG, por sus siglas en inglés- (CEPAL, 2020a; World Bank, 2019) la acumulación de déficits fiscales en Latinoamérica aumentó la deuda pública de los gobiernos centrales que en 2019 promedió un $44,8 \%$ del Producto Interno Bruto (PIB), un incremento de 15 puntos porcentuales respecto a su mínimo del 29,8\% del PIB en 2011.

Existe gran heterogeneidad entre países. Mientras el Paraguay y el Perú tenían niveles de endeudamiento inferiores al 25\% del PIB a finales de 2019, otros países presentaban niveles mucho mayores, que alcanzaban el 89,4\% en la Argentina, el 75,8 \% en el Brasil y el 61,3\% en Costa Rica (CEPAL, 2020b).

Si bien el comercio mundial ya se estaba desacelerando, el tráfico comercial venia en caída por segundo año consecutivo antes del brote del coronavirus (CEPAL, 2019a). En 2019, el volumen del comercio mundial de bienes cayó un $0,4 \%$, su primera disminución desde la crisis financiera mundial del 2008 y 2009. En gran medida, ello se debió a la progresiva acumulación de barreras comerciales primordialmente entre los Estados Unidos y China desde principios de 2018 y su efecto dominó en las cadenas globales de valor altamente interconectadas (Nuguer \& Powell, 2020; Peñafiel, 2021).

Según el Banco Mundial (2020) y CEPAL (2020b), la caída de la actividad económica mundial —en particular de los Estados Unidos, China y Europatiene un impacto negativo en América Latina y el Caribe no solo porque se produce en un momento en que el crecimiento de la región ha disminuido 
Peñafiel Chang: Panorama económico, político y sanitario de América Latina y el Caribe...

considerablemente — del 1,1\% en 2018 al 0,1\% en 2019- sino también porque son los países exportadores de petróleo los que experimentarán la mayor pérdida en el valor de ventas al exterior, ya que sus costos de producción son más altos que los de muchos otros productores y, por lo tanto, tienen menos capacidad para soportar un período prolongado de precios bajos. La Figura 2 muestra la evolución de los precios de productos primarios.

Figura 2. Precios de productos primarios, enero de 2003 a marzo de 2020

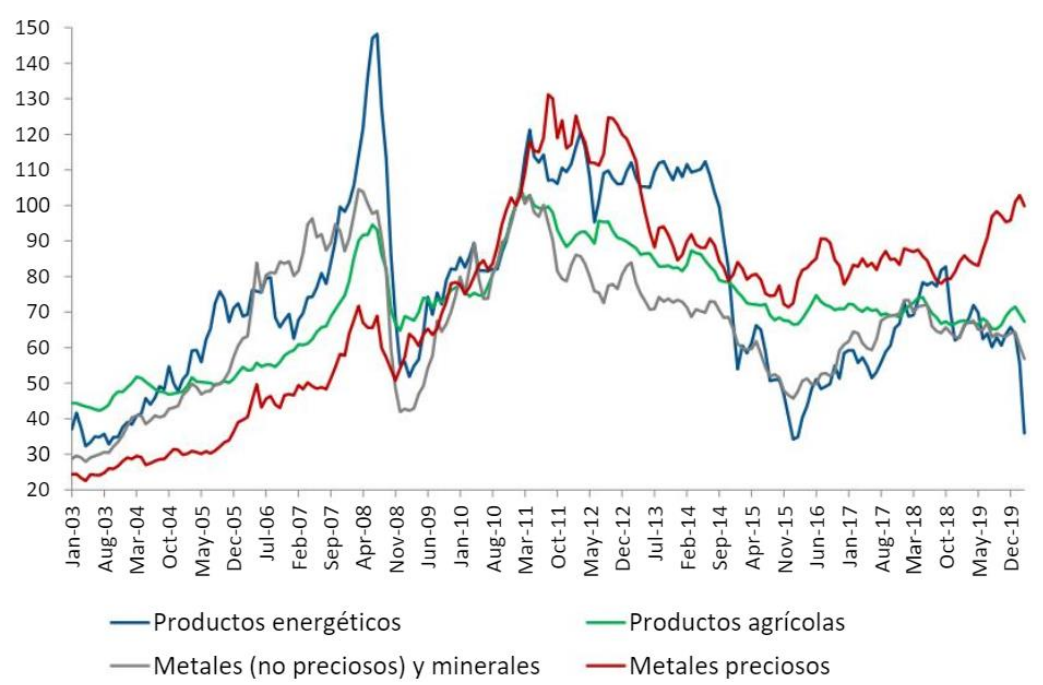

Nota: Índice enero de $2011=100$.

Fuente: CEPAL (2020b).

Por otra parte, la crisis del COVID-19 también puede causar un impacto sobre las importaciones utilizadas para producir exportaciones, como son los casos de México y Chile que serían los países más expuestos a una caída de la oferta de China — dado que suministra alrededor del 7\% de sus insumos intermedios- Le siguen Colombia y Perú, que importan de China el 4,5\% y el $5 \%$ de sus insumos intermedios, respectivamente.

México es el país más expuesto a los cambios en las condiciones de la oferta y la demanda en los Estados Unidos, especialmente en el sector manufacturero. Costa Rica también está muy expuesta a las condiciones económicas de los 
Estados Unidos, ya que alrededor del 10\% de su PIB depende de la oferta y la demanda de ese país. Los países más expuestos a los cambios en las condiciones de la oferta y la demanda en la Unión Europea son Chile, México y el Brasil, ya que alrededor del $5 \%$ de su PIB depende del valor añadido de los sectores de servicios y manufacturas en ese mercado (CEPAL, 2020a). La Figura 3 expone lo señalado:

Figura 3. Efectos del COVID-19 en las exportaciones de bienes por subregiones en América Latina y el Caribe 2020 (Variación porcentual)

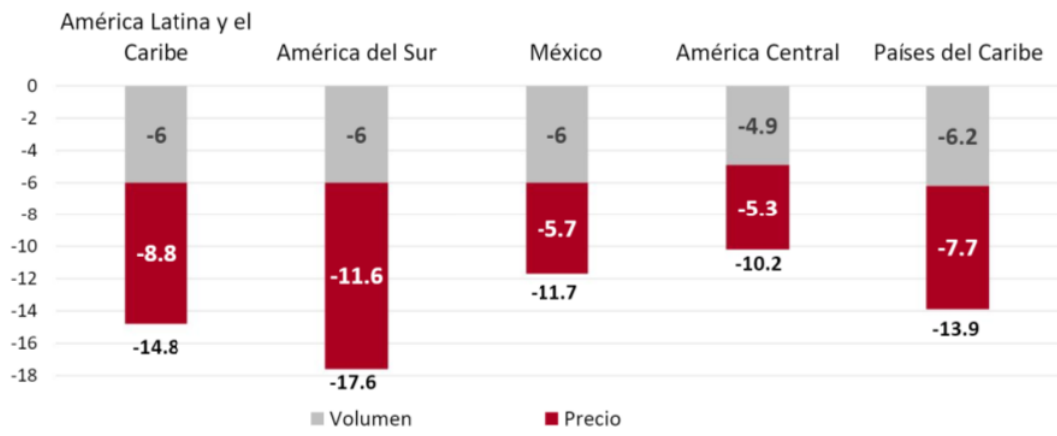

Fuente: CEPAL (2020b).

Todo este escenario se da mientras los gobiernos de la región presentan graves problemas de funcionamiento y debilidad política, especialmente tras las últimas protestas sociales en Argentina, Bolivia, Chile, Colombia, Perú y Ecuador, dadas las desigualdades económicas-sociales; justamente, una de las áreas que se está poniendo a prueba con la crisis del COVID-19 son los servicios públicos, particularmente el Sanitario (Malamud \& Núñez, 2020).

Generalmente, los sistemas de salud en América Latina y el caribe se organizan en torno a servicios en el sector público para las personas de bajos ingresos, servicios del seguro social para los trabajadores formales y servicios privados para quienes puedan costearlos (Peñafiel et al., 2020). Además, los sistemas de salud tienden a ser geográficamente centralizados, con servicios y médicos especializados concentrados en pocos centros urbanos (Figura 4). De esta manera, los sistemas permanecen segregados y claramente desiguales al ofrecer servicios de distinta calidad a diferentes grupos poblacionales (Pan 
Peñafiel Chang: Panorama económico, político y sanitario de América Latina y el Caribe...

American Health Organization [PAHO] \& World Health Organization [WHO], 2020a; PAHO \& WHO, 2020b).

Figura 4. Equidad en el acceso a la salud en América Latina y el Caribe

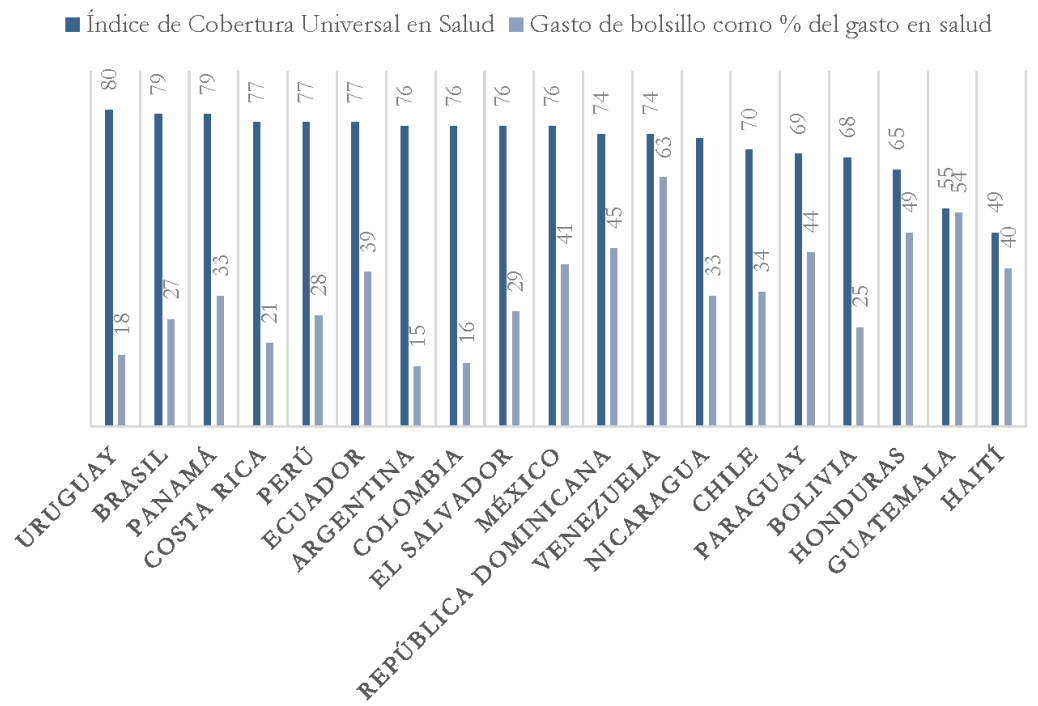

Nota: al 10 de abril de 2020.

Fuente: Peñafiel et al. (2020).

Dado lo anterior, la mayoría de los países de la región se caracterizan por tener sistemas de salud débiles y fragmentados, que no garantizan el acceso universal necesario para hacer frente a la crisis sanitaria del COVID-19. Además, América Latina destina mucho menos recursos a la salud comparada con Europa. Mientras Reino Unido invierte 7,9\%, España $8 \%$ y Alemania $10 \%$ del PIB en salud pública, la región en promedio solo invierte el 3,5\% del PIB (Peñafiel et al., 2020).

Según la PAHO y WHO (2020c), en promedio, la Unión Europea invierte USD 3364 por persona, entre tanto América Latina invierte tres veces menos. Sin embargo, desde la perspectiva de letalidad del COVID-19 los indicadores clave para evaluar qué tan bien estuvo preparada la región en materia de infraestructura sanitaria son los ventiladores mecánicos y las camas hospitalarias, siendo el respirador incluso más importante al brindar soporte 
técnico para suplir la función respiratoria que permite atender a los pacientes en su modo más grave (Fahmi, 2020). La Figura 5 muestra la infraestructura que tiene Latinoamérica para enfrentar al coronavirus.

Figura 5. Infraestructura básica para enfrentar el coronavirus en América Latina y el Caribe

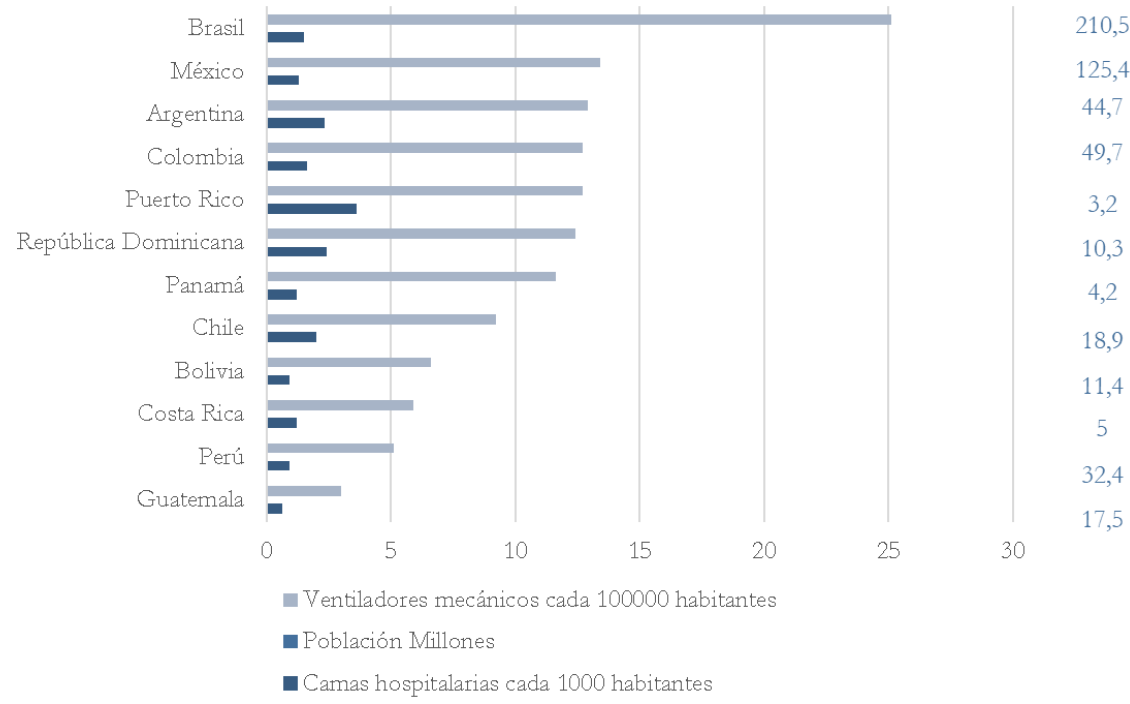

Fuente: Peñafiel et al. (2020).

Por otra parte, entre los países que mejor han manejado la situación en el mundo son Alemania, Corea del sur y Japón, no solo al tener una baja tasa de mortalidad, sino porque —además — se han identificado algunas de las razones que pueden estar haciendo la diferencia, como el tiempo de reacción y la capacidad de pruebas masivas (Arab-Mazar, et al., 2020; Dong et al., 2020; Peñafiel, 2021; The Lancet Respiratory Medicine, 2020; Walker et al., 2020; Zhang et al., 2020).

Mientras Alemania tiene la capacidad de realizar alrededor de veinte mil pruebas Covid-19 por millón de habitantes, América Latina solamente realiza en promedio tres mil y — dada la magnitud de velocidad de contagio— están en la necesidad de importar pruebas rápidas (Ji et al., 2020; Xu et al., 2020). Un elemento a favor de la región es la estructura demográfica joven a diferencia de 
Peñafiel Chang: Panorama económico, político y sanitario de América Latina y el Caribe...

las demás regiones del mundo y por lo que se sabe del virus es mucho más letal en la población de adultos mayores.

\section{Metodología}

La investigación según el objeto de estudio es exploratoria, de método inductivo y de corte transversal, cuyo principal objetivo es reducir la dimensionalidad de un grupo de variables mediante la aplicación de los componentes principales (CP) y clúster, complementadas —además- con las representaciones gráficas de Biplot y dendrogramas de un conjunto de países de América Latina y el Caribe, de tal forma que se adquiere una mejor percepción respecto del panorama de América Latina frente al COVID-19 en sus comienzos (Hernández et al., 2010). Los CP son un nuevo conjunto de variables las cuales son incorreladas y se ordenan de tal manera que las primeras retienen la mayor cantidad de información de las variables originales, otra manera de verlo es reducir el número de variables iniciales y obtener un conjunto de menor número denominado $\mathrm{CP}$ las cuales son combinaciones lineales de las primeras.

En líneas generales se acepta que los precursores de la técnica del análisis en CP fueron Pearson (1901) y Hotelling (1933), ambos desde perspectivas diferentes ${ }^{1}$. En este artículo se siguieron los lineamientos de Pearson (1901), el cual halla líneas y planos que mejor se ajustan un conjunto de puntos en espacios p-dimensionales, así como el problema geométrico de optimización que conduce al cálculo de los CP.

Siguiendo la metodología propuesta por Cadima et al. (2004), Wright et al. (2009) y Jollife y Cadima (2016), partimos de una matriz de datos $X$, de $n$ individuos por $p$ variables tal como sigue:

1 Hotelling (1933) define CP como la proyección ortogonal de los datos en un espacio dimensional inferior (subespacio principal), de modo que se maximice la varianza de los datos proyectados. 


$$
X=\left[\begin{array}{cccc}
x_{11} & x_{12} & \ldots & x_{1 p} \\
x_{21} & x_{22} & \cdots & x_{2 p} \\
x_{31} & x_{32} & \cdots & x_{3 p} \\
\vdots & \vdots & & \vdots \\
x_{n 1} & x_{n 2} & \cdots & x_{n p}
\end{array}\right]
$$

Y sea $\boldsymbol{D}$ la matriz de varianzas- covarianzas de $\boldsymbol{X}$ :

$$
D=\left[\begin{array}{cccc}
\sigma_{11}^{2} & \sigma_{12}^{2} & \cdots & \sigma_{1 p}^{2} \\
\sigma_{21}^{2} & \sigma_{22}^{2} & \cdots & \sigma_{p 2}^{2} \\
\sigma_{31}^{2} & \sigma_{32}^{2} & & \sigma_{3 p}^{2} \\
\vdots & \vdots & & \vdots \\
\sigma_{p 1}^{2} & \sigma_{2 p}^{2} & \cdots & \sigma_{p p}^{2}
\end{array}\right]
$$

Llamando $B_{i}$ a las nuevas variables con $i=\ldots, p ; \bar{B}_{i}$ a los vectores de datos $\mathrm{y} \bar{r}_{i}$ a los vectores de coeficientes tenemos que:

$$
\overline{B_{i}}=X \bar{r}_{i}
$$

donde:

$$
\overline{B_{i}}=\left[\begin{array}{c}
b_{1 i} \\
b_{2 i} \\
b_{3 i} \\
\vdots \\
b_{n i}
\end{array}\right] \bar{r}_{i}=\left[\begin{array}{c}
r_{1 i} \\
r_{2 i} \\
r_{3 i} \\
\vdots \\
r_{n i}
\end{array}\right]
$$

Con lo que la nueva matriz de datos queda:

$$
B=\left[\begin{array}{cccc}
B_{11} & B_{12} & \ldots & B_{1 p} \\
B_{21} & B_{22} & \ldots & B_{2 p} \\
B_{31} & B_{32} & \ldots & B_{3 p} \\
\vdots & \vdots & \vdots & \vdots \\
B_{n 1} & B_{n 2} & \ldots & B_{n p}
\end{array}\right]
$$


Peñafiel Chang: Panorama económico, político y sanitario de América Latina y el Caribe...

donde — por ejemplo_ - para el primer individuo tenemos:

$$
\bar{B}_{1}=\left[\begin{array}{c}
b_{11} \\
b_{21} \\
b_{31} \\
\vdots \\
b_{n 1}
\end{array}\right]=\left[\begin{array}{cccc}
x_{11} & x_{12} & \ldots & x_{1 p} \\
x_{21} & x_{22} & \ldots & x_{2 p} \\
x_{31} & x_{32} & \ldots & x_{3 p} \\
\vdots & \vdots & \vdots & \vdots \\
x_{n 1} & x_{n 2} & \ldots & x_{n p}
\end{array}\right]\left[\begin{array}{c}
r_{11} \\
r_{21} \\
r_{31} \\
\vdots \\
r_{n 1}
\end{array}\right]
$$

Antes de empezar a calcular la primera componente, debemos hacer algunas consideraciones previas:

$$
\operatorname{Var}\left[B_{i}\right]=\frac{\sum_{j=1}^{n} b_{i j}^{2}}{n}=\frac{\bar{B}_{i}^{\prime} \bar{B}_{i}}{n}=\frac{\bar{r}_{i}^{\prime} X^{\prime} X \bar{r}_{i}}{n}=\bar{r}_{i}^{\prime} \frac{X^{\prime} X}{n} \bar{r}_{i}=\bar{r}_{i}^{\prime} D \bar{r}_{i} .
$$

Y, en general:

$$
\operatorname{Var}[X \bar{r}]=\bar{r}^{\prime} D \bar{r}
$$

La primera componente $\bar{B}_{1}$ se obtiene de forma que su varianza sea máxima y sujeta a la restricción de que el vector $r_{1}$ sea unitario. Se nos plantea un problema de optimización formulado así:

$$
\underset{\bar{r}_{1}^{\prime} \bar{r}_{1}=1}{\operatorname{Váx}} \operatorname{Var}\left[\bar{B}_{1}\right]=\bar{r}_{1}^{\prime} D \bar{r}_{1}
$$

Aplicamos los multiplicadores de Lagrange para resolverlo. Sea $L$ la función de Lagrange definida como sigue:

$$
\begin{gathered}
L=\bar{r}_{1}^{\prime} D \bar{r}_{1}-\lambda\left(\bar{r}_{1}^{\prime} \bar{r}_{1}-1\right)=\bar{r}_{1}^{\prime} D \bar{r}_{1}-\lambda \bar{r}_{1}^{\prime} \bar{r}_{1}+\lambda \\
\frac{d L}{d \bar{r}_{1}}=2 D \bar{r}_{1}-2 \lambda \bar{r}_{1}=0 \\
(D-\lambda I) \bar{r}_{1}=0
\end{gathered}
$$

Para resolver $(D-\lambda I) \bar{r}_{1}=0$, hemos de tener en cuenta que un sistema homogéneo en $r_{1}$ solo tiene solución si el determinante de la matriz de los 
coeficientes es nulo: $(\mid D-\lambda I) \mid=0$ y esto significa que $\lambda$ es autovalor de $D$. Premultiplicando la ecuación 12 por $\bar{r}_{1}^{\prime}$ nos queda:

$$
\bar{r}_{1}^{\prime}(D-\lambda I) \bar{r}_{1}=\bar{r}_{1}^{\prime} D \bar{r}_{1} \lambda \bar{r}_{1}^{\prime} \bar{r}_{1}=0
$$

Aplicando la ecuación 9, obtenemos que $\bar{r}_{1}^{\prime} D \bar{r}_{1}=\lambda$. Y tenemos que dicho valor propio maximiza la varianza, es decir, bastaría con tomar el autovalor más grande de D. Luego la primera componente es $\bar{B}_{1}=X \bar{r}_{1}$ donde $\bar{r}_{1}$ es un autovector.

Luego procediendo de igual manera, pero añadiendo una nueva restricción, se calcula el segundo componente y — como las componentes han de ser incorreladas - se verifica que:

$$
0=E\left[B_{2}^{\prime} B_{1}\right]=E\left[\bar{r}_{2}^{\prime} X^{\prime} X \bar{r}_{1}\right]=\bar{r}_{2}^{\prime} D \bar{r}_{1} .
$$

Como $\bar{r}_{1}$ es un autovector de $D$, por definición de autovector: $D \bar{r}_{1}=\lambda \bar{r}_{1}$ y multiplicando por $\bar{r}_{2}^{\prime}$ se deduce lo siguiente:

$$
\bar{r}_{2}^{\prime} \lambda \bar{r}_{1}=\lambda \bar{r}_{2}^{\prime} \bar{r}_{1}=0
$$

donde $\bar{r}_{2}^{\prime} \bar{r}_{1}=0$ y son ortogonales. Por otro lado, el problema de optimización de la segunda componente queda formulado de la siguiente manera:

$$
\left\{\begin{array}{c}
\text { máx } \\
\bar{r}_{2}^{\prime} \bar{r}_{1}=0 \operatorname{Var}\left[\overline{B_{2}}\right]=\bar{r}_{2}^{\prime} D \bar{r}_{2} . \\
\bar{r}_{2}^{\prime} \bar{r}_{2}=1
\end{array}\right.
$$

Aplicando multiplicador de Lagrange tenemos:

$$
\begin{gathered}
L=\bar{r}_{2}^{\prime} D \bar{r}_{2}-\lambda_{2}\left(\bar{r}_{2}^{\prime} \bar{r}_{2}-1\right) \beta \bar{r}_{2}^{\prime} \bar{r}_{1} \\
\frac{d L}{d \bar{r}_{2}}=2 D \bar{r}_{2}-2 \lambda_{2} \bar{r}_{2}-\beta \bar{r}_{1}=0
\end{gathered}
$$

Premultiplicando por $\bar{r}_{1}^{\prime}$ y usando la ecuación 9 de vector unitario y ecuación 16 de ortogonalidad para obtener la siguiente ecuación:

$$
2 \bar{r}_{1}^{\prime} D \bar{r}_{2}-2 \lambda_{2} \bar{r}_{1}^{\prime} \bar{r}_{2}-\beta \bar{r}_{1}^{\prime} \bar{r}_{1}
$$


Peñafiel Chang: Panorama económico, político y sanitario de América Latina y el Caribe...

$$
2 \bar{r}_{1}^{\prime} D \bar{r}_{2}=0
$$

Debido a que $\bar{r}_{1}^{\prime} D=\lambda \bar{r}_{1}^{\prime}$, si multiplicamos por $\bar{r}_{2}$ y aplicamos la ortogonalidad de ambos vectores, se obtiene que $\beta=0$. Volviendo a la ecuación 18 se tiene:

$$
D \bar{r}_{2}-\lambda_{2} \bar{r}_{2}=0
$$

y tenemos que $\left(D-\lambda_{2}\right) \bar{r}_{2}=0$. Aplicando el mismo razonamiento tenemos que $\lambda_{2}$ es autovalor y maximiza la varianza teniendo en cuenta que $\left(\lambda>\lambda_{2}\right)$ y si seguimos aplicando este razonamiento. En general, la ecuación $|(D-\lambda I)|=0$ tiene $(n)$ autovalores que maximizan la varianza $\lambda_{1}, \lambda_{2}, \lambda_{3}, \ldots, \lambda_{n}$ ordenadas de mayor a menor $\lambda_{1}>\lambda_{2}>\lambda_{3}>\cdots>\lambda_{n}$. Siendo así, el componente principal $h$-ésimo se define como $\bar{B}_{h}=X \bar{r}_{h}$ donde $\bar{r}_{h}$ es el autovector de $\mathrm{D}$ asociado a su $h$-ésimo mayor valor propio con lo que concluye la demostración.

Por su parte, los clústeres son un método del análisis multivariado que permite reducir una cantidad de información en grupos donde los miembros de cada uno de ellos comparten características similares (Anderson et al., 2004; Chen et al., 2010; Morales \& Morales, 2019). En este artículo, los grupos se forman bajo el criterio de clúster jerárquico de encadenamiento completo, el cual plantea que a partir de una matriz de distancias y similaridad entre los elementos de la muestra se construye una jerarquía basada en estas distancias.

La distancia utilizada es la euclídea y el coeficiente de similaridad entre dos elementos $i$ y $h$, en base a la variable $j$ se define como una función $S_{j i h}$ no negativa y simétrica que satisface:

$$
S_{j i i}=1 \quad 0 \leq S_{j i h} \leq 1, \quad S_{j i h}=S_{j h i} .
$$

Si obtenemos la similaridad entre dos elementos para cada variable podemos combinarlas en un coeficiente de similaridad global entre los dos elementos. El coeficiente propuesto por Gower (1971).

$$
S_{j i h}=\frac{\sum_{j=1}^{p} W_{j i h} S_{j i h}}{\sum_{j=1}^{p} W_{j i h}},
$$


donde, $W_{j i h}$ es una variable dummy que es igual a 1 si la comparación de estos dos elementos mediante la variable $j$ tiene sentido y será igual a cero si no queremos incluir esta variable en la comparación.

Por otro lado, el biplot —introducido por Gabriel (1971) — es una representación gráfica simultánea de los individuos mediante puntos y las variables mediante flechas en un mismo sistema de coordenadas bidimensional construido en base a las dos primeras componentes principales.

Esta herramienta permite interpretar el significado de las componentes en el eje horizontal y el eje vertical con base a las direcciones de las flechas. A su vez, se valoran como parecidos los individuos cuyos puntos están próximos en el biplot y de igual modo tendrán correlación positiva las variables con flechas semejantes. Este artículo se basó en la metodología propuesta por Cárdenas et al. (2007) y Torres et al. (2013).

Por último, el dendrograma —o también llamado gráfico jerárquico-, es una representación gráfica del resultado del proceso de agrupamiento en forma de árbol. Los criterios para definir distancias que se ha presentado tiene la propiedad de que, si consideramos tres grupos $A, B, C$ se verifica:

$$
d(A, C) \leq \operatorname{máx}[d(A, B) ; d(B, C)] .
$$

Siendo así, una medida de distancia que tiene esta propiedad se denomina ultramétrica, es decir, una propiedad más fuerte que el cumplimiento de la desigualdad triangular. En efecto si $d(A, C)$ es menor o igual que el máximo entre $d(A, B)$ y $d(B, C)$ forzosamente será menor o igual que la suma $d(A, B)+d(B, C)$. Por lo cual el dendrograma ${ }^{2}$ es la representación de una ultramétrica.

2 El dendrograma se construye así: i) los n elementos iniciales están dispuestos en la parte inferior del gráfico ii) las uniones entre elementos se indican mediante líneas rectas, dos dirigidas a los elementos que se unen y que son perpendiculares al eje de los elementos y uno Paralelo a este eje que se ubica en el nivel donde se unen iii) se repite el proceso hasta que todos los elementos estén conectados por líneas rectas. Finalmente, si cortamos el dendrograma a un nivel de distancia dado, obtenemos una clasificación de los elementos en los grupos existentes en ese nivel y los elementos que lo forman. 
Peñafiel Chang: Panorama económico, político y sanitario de América Latina y el Caribe...

\section{Resultados}

Cuando se estudia un fenómeno tan complejo como una pandemia mundial sin precedentes, se encuentra el dilema teórico o metodológico sobre qué variables deben ser consideradas para que su explicación incluya no solo aspectos económicos, sociales entre otros sino también que cuenten con una sustentación teórica. Ante esta circunstancia, el análisis del panorama de América Latina y el Caribe mediante métodos cuantitativos que ayuden a agrupar países a partir de características similares auxilian al investigador a resumir grandes cantidades de variables que pueden estar correlacionadas en pocos componentes que lo simplifiquen.

En tal contexto, el enfoque utilizado es cuantitativo debido a que se utilizó información económica, social, sanitaria y política con corte transversal del 2020 de diversas fuentes como es el caso para datos de COVID19 obtenidas de: La Inteligencia de Salud Global, la Universidad Johns Hopkins y Medidores del Mundo. En cuanto a datos económicos, sociales y políticos la fuente es la Comisión Económica para América Latina y el Caribe, la Organización Transparencia Internacional, la consultora Marsh y la Organización Mundial de la Salud.

Este estudio considera dieciocho países de la región, los cuales son Argentina, Bolivia, Brasil, Chile, Colombia, Costa Rica, Ecuador, El Salvador, Guatemala, Honduras, México, Nicaragua, Panamá, Paraguay, Perú, República Dominicana, Uruguay, Venezuela, y once variables:

El gasto público en salud como porcentaje del PIB, que comprende el gasto recurrente y de capital proveniente de los presupuestos públicos. La segunda variable es el gasto privado en salud como porcentaje del PIB, que comprende el gasto recurrente y de capital proveniente de los presupuestos privados. La tercera, es el gasto per cápita en salud, que es la suma de los gastos de salud públicos y privados como proporción de la población total. La cuarta corresponde al índice de cobertura universal en salud, que implica a todas las personas y comunidades con acceso sin discriminación alguna a servicios integrales de salud. 
Por su parte, variable es el gasto de bolsillo como porcentaje del gasto en salud, es la quinta variable, que es el pago de bienes y servicios del sector salud que no cubre la asistencia pública. La sexta variable comprende los casos confirmados por COVID-19 al diez de abril del 2020, mientras que para la séptima son las camas hospitalarias por cada mil habitantes que es una medida general de la disponibilidad del servicio para pacientes internados.

La octava variable es la tasa de mortalidad por COVID-19, que se refiere a la proporción de fallecimientos en un periodo en una población concreta. La novena variable es la prueba de COVID-19 por cada millón de habitantes. Luego, la décima comprende al índice de percepción de corrupción, que clasifica a los países por sus niveles percibidos de corrupción en el sector público. Finalmente, la décimo primera variable es el índice de riesgo político, que evalúa el riesgo de inestabilidad económica y los efectos potenciales que esto puede tener en las empresas que operan en el país o territorio. Todas estas variables seleccionadas permiten acrecentar la cantidad de observaciones y cubrir un deseable panorama de América Latina y el caribe frente al COVID-19.

$\mathrm{Al}$ integrar las once variables mediante el $\mathrm{CP}$, se tienen los resultados que aparecen en la Tabla 1, en donde se observa que el primer factor explica el $44,14 \%$ del total de la varianza, el segundo el $16,72 \%$ y el tercero el $11,97 \%$ y los demás menos del $9 \%$ del total de la inercia cada uno. De allí, la determinación del número de componentes a retener es —en parte arbitraria- y queda a juicio del investigador; sin embargo, en este artículo se usa el criterio Kaiser (1960) el cual conserva los componentes cuyos valores propios son mayores a la unidad, siendo así se toma los tres primeros componentes que explica el $72,83 \%$ del total de la inercia.

Con base en la metodología de CP, la Tabla 2 consigue caracterizar cada componente, donde cada columna representa una combinación lineal de las variables originales. Dicho de otro modo, es la relación de la cantidad de información que cada componente representa de una variable específica.

Mediante los pesos de cada variable sobre cada componente los modelos quedan establecidos de la siguiente forma: 
Peñafiel Chang: Panorama económico, político y sanitario de América Latina y el Caribe...

Tabla 1. Componentes principales / correlación

\begin{tabular}{lcccc}
\hline Componente & Valor Propio & Diferencia & Proporción & Acumulativa \\
\hline Comp1 & 4,8548 & 3,0151 & 0,4414 & 0,4414 \\
Comp2 & 1,8397 & 0,5235 & 0,1672 & 0,6086 \\
Comp3 & 1,3161 & 0,3414 & 0,1197 & 0,7283 \\
Comp4 & 0,9747 & 0,2049 & 0,0886 & 0,8169 \\
Comp5 & 0,7698 & 0,2173 & 0,0700 & 0,8868 \\
Comp6 & 0,5524 & 0,2488 & 0,0502 & 0,9371 \\
Comp7 & 0,3035 & 0,0796 & 0,0276 & 0,9647 \\
Comp8 & 0,2239 & 0,1193 & 0,0204 & 0,9850 \\
Comp9 & 0,1045 & 0,0729 & 0,0095 & 0,9945 \\
Comp10 & 0,0315 & 0,0029 & 0,0029 & 0,9974 \\
Comp11 & 0,0286 & & 0,0026 & 1,0000 \\
\hline
\end{tabular}

Nota: la primera columna contiene a cada uno de los componentes. La segunda columna representa los pesos de cada componente. La tercera columna es la diferencia de pesos entre dos componentes. La cuarta columna indica la capacidad de captación de varianza de cada componente. La quinta columna muestra la captación acumulada de varianza.

Fuente: elaboración propia.

\section{Primer Componente}

$$
\begin{aligned}
(C P 1)= & 0,361 \operatorname{var} 1-0,043 \operatorname{var} 2+0,414 \operatorname{var} 3+0,263 \operatorname{var} 4 \\
& -0,351 \operatorname{var} 5+0,141 \operatorname{var} 6+0,337 \operatorname{var} 7-0,231 \operatorname{var} 8 \\
& -0,059 \operatorname{var} 9+0,409 \operatorname{var} 10+0,384 \operatorname{var} 11,
\end{aligned}
$$

el cual explica el 44,14\% del total de la varianza y allí sobresalen por su aporte las siguientes variables: el gasto público en salud \% PIB (var1), gasto per cápita en salud (var3), índice de cobertura universal en salud (var4), camas hospitalarias por cada mil habitantes (var7), índice de percepción de corrupción (var10) e índice de riesgo político (var11) todas ellas con correlaciones positivas mientras que para el gasto de bolsillo como porcentaje del gasto en salud (var5) y tasa de mortalidad por COVID-19 (var8) con correlación negativa, por lo tanto, este factor puede ser considerado como 
Tabla 2. Componentes Principales (vectores propios)

\begin{tabular}{lcccccccccccc}
\hline Variable & Com1 & Comp2 & Comp3 & Comp4 & Comp5 & Comp6 & Comp7 & Comp8 & Comp9 & Comp10 & Comp11 \\
\hline Var1 & 0,3615 & $-0,226$ & 0,013 & $-0,319$ & 0,332 & 0,190 & 0,416 & 0,046 & $-0,108$ & 0,619 & $-0,036$ \\
Var2 & $-0,043$ & 0,635 & 0,227 & $-0,071$ & 0,400 & 0,037 & 0,324 & 0,221 & 0,024 & $-0,264$ & $-0,387$ \\
Var3 & 0,414 & 0,085 & 0,062 & 0,229 & 0,159 & $-0,070$ & $-0,137$ & $-0,055$ & $-0,802$ & $-0,191$ & 0,179 \\
Var4 & 0,263 & $-0,199$ & 0,471 & $-0,065$ & $-0,503$ & $-0,143$ & 0,338 & 0,471 & 0,025 & $-0,209$ & 0,095 \\
Var5 & $-0,351$ & 0,202 & $-0,014$ & 0,520 & 0,092 & $-0,037$ & 0,244 & 0,331 & $-0,023$ & 0,347 & 0,513 \\
Var6 & 0,141 & 0,491 & 0,463 & $-0,051$ & $-0,335$ & 0,241 & $-0,121$ & $-0,446$ & 0,078 & 0,307 & 0,187 \\
Var7 & 0,337 & 0,065 & 0,079 & 0,240 & 0,139 & $-0,787$ & $-0,084$ & $-0,125$ & 0,291 & 0,226 & $-0,137$ \\
Var8 & $-0,231$ & $-0,169$ & 0,495 & $-0,388$ & 0,459 & $-0,148$ & $-0,348$ & 0,087 & 0,054 & $-0,080$ & 0,388 \\
Var9 & $-0,059$ & $-0,392$ & 0,471 & 0,571 & 0,181 & 0,316 & $-0,069$ & $-0,102$ & 0,065 & 0,023 & $-0,374$ \\
Var10 & 0,409 & $-0,043$ & $-0,128$ & 0,155 & 0,254 & 0,229 & 0,233 & $-0,223$ & 0,445 & $-0,417$ & 0,442 \\
Var11 & 0,384 & 0,162 & $-0,124$ & 0,062 & 0,025 & 0,286 & $-0,570$ & 0,575 & 0,215 & 0,146 & $-0,043$ \\
\hline
\end{tabular}

Nota: las columnas ( 2 al 11) representan los pesos estimados de cada componente respecto a cada variable. Fuente: elaboración propia.

infraestructura sanitaria indicando que globalmente un aumento en dichas variables involucra mejores condiciones sanitarias.

Segundo Componente

$$
\begin{aligned}
(C P 2)= & -0,226 \operatorname{var} 1+0,635 \operatorname{var} 2+0,085 \operatorname{var} 3-0,199 \operatorname{var} 4 \\
& +0,202 \operatorname{var} 5+0,491 \operatorname{var} 6+0,065 \operatorname{var} 7-0,169 \operatorname{var} 8 \\
& -0,392 \operatorname{var} 9-0,043 \operatorname{var} 10+0,162 \operatorname{var} 11 .
\end{aligned}
$$

Este componente explica el 16,72\% de la varianza total donde sobresalen por su aporte las siguientes variables: gasto privado en Salud\% PIB (var2), gasto de bolsillo como porcentaje del gasto en salud (var5), casos confirmados por COVID-19 (var6), todas con correlaciones positivas y, por otro lado, gasto público en salud como porcentaje del PIB y Test de COVID-19 por cada millón de habitantes (var9) con relación negativa. A este componente se le puede considerar como estado de adversidad, por lo que sugiere que los países con mayores puntuaciones en este eje son los que más han sido golpeados por el virus. 
Peñafiel Chang: Panorama económico, político y sanitario de América Latina y el Caribe...

Tercer componente

$$
\begin{aligned}
(C P 3)= & 0,013 \operatorname{var} 1+0,227 \operatorname{var} 2+0,062 \operatorname{var} 3+0,471 \operatorname{var} 4 \\
& -0,014 \operatorname{var} 5+0,463 \operatorname{var} 6+0,079 \operatorname{var} 7+0,495 \operatorname{var} 8 \\
& +0,471 \operatorname{var} 9-0,128 \operatorname{var} 10-0,124 \operatorname{var} 11
\end{aligned}
$$

Este componente explica el 11,97\% de la varianza total, donde sobresalen por su aporte las siguientes variables: gasto privado en Salud\% PIB (var2), índice de cobertura universal en salud (var4), casos confirmados por COVID19 (var6), tasa de mortalidad por COVID-19 (var8), prueba de COVID-19 por cada millón de habitantes (var9) todas con correlación positiva mientras que para el índice de percepción de corrupción (var10) e índice de riesgo político (var11) con relación negativa. Este componente se denominó plan de contingencia y sintetiza la información de aquellos países con mejor gestión al inicio de la pandemia en sus territorios.

Adicionalmente, el predominio de las variables en cada uno de los componentes se observa gráficamente mediante el biplot (ver Figura 6), el cual no busca la proximidad entre las observaciones y variables, sino más bien son las direcciones de las flechas (variables) lo que agrega valor al análisis. Esta herramienta ratifica los grupos de variables en cada componente.

En la Figura 6 se observa que las variables 1, 3, 4, 7, 10 y 11 están fuertemente correlacionadas y son indicadores referentes a la cobertura de salud, infraestructura sanitaria, estabilidad política y corrupción. Por otro lado, las variables 6, 8, 9 están relacionadas al COVID-19 y las variables 2 y 5 son indicadores de países donde las personas tienen que gastar de su presupuesto para compensar las deficiencias de la salud pública. En cuanto a la dirección de las flechas, cuando están hacia la izquierda o derecha es porque están correlacionadas o inversamente correlacionadas al componente 1. Así mismo, cuando la dirección es hacia arriba o abajo se está interpretando la correlación con el componente 2 .

Si se toma como ejemplo a Uruguay, se observa que este se encuentra por encima del promedio en cuanto a cobertura de salud e infraestructura sanitaria pública, y además cuenta con los mejores indicadores de estabilidad política e índices de corrupción. Por otro lado, también se distingue que este 
país es donde menos se gasta del presupuesto de las personas para compensar la calidad de la salud pública. A la vez, se observa que Uruguay tiene la tasa de contagio, el número de pruebas y la cantidad de infectados por el COVID-19 dentro del promedio de la región.

Figura 6. Representación conjunta de filas y columnas de la matriz de datos en el biplot

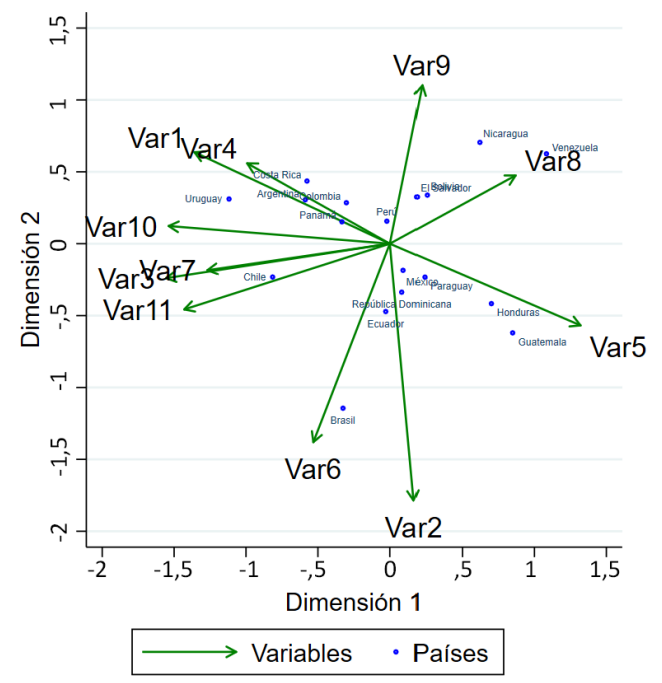

Nota: cada punto representa un país. La variable del resultado en el eje horizontal es el componente uno y la variable del resultado en el eje vertical representa el componente dos. Las líneas con flechas azules representan a las variables con su respectiva pendiente y coeficiente respecto a cada componente.

Fuente: elaboración propia.

Mientras tanto, Guatemala y Honduras están por encima del promedio en cuanto al gasto que necesitan realizar las personas para compensar la calidad de la salud pública. Estos países también cuentan con menor infraestructura sanitaria pública y están entre aquellos con peores indicadores de estabilidad política y corrupción. Pese a ello, se observa que tienen la tasa de contagio, el número de pruebas y la cantidad de infectados dentro del promedio de la región por el COVID-19.

Casos aparte son por un lado Brasil, donde se observa que - a pesar de tener indicadores sanitarios ligeramente por encima del promedio- la indiferencia política y su gestión ante la pandemia ha provocado que sea 
Peñafiel Chang: Panorama económico, político y sanitario de América Latina y el Caribe...

el país con más casos confirmados por COVID-19, y por otro Venezuela y Nicaragua, ya que la veracidad de los datos oficiales que entregan en cuentagotas estas naciones está siendo fuertemente cuestionada.

Por último, con el fin de visualizar características nuevas o relaciones que no se habían previsto de antemano, se agruparon los países atendiendo las diferentes variables mediante un análisis de clúster jerárquico de encadenamiento completo representado en un dendrograma. El objetivo es agrupar a los países considerando las variables de análisis, pero no se puede reducir todos a un solo grupo, de modo que será preciso detener el proceso de agrupamiento en un punto determinado. Considerando que distancias pequeñas indican conglomerados homogéneos y que grandes distancias definen conglomerados heterogéneos, se toma la medida de disimilitud de 3 (Figura 7). A continuación, se presenta la separación de seis conglomerados agrupando a países con máxima homogeneidad dentro de cada grupo y la mayor diferencia entre grupos.

Figura 7. Dendrograma para el análisis de conglomerados

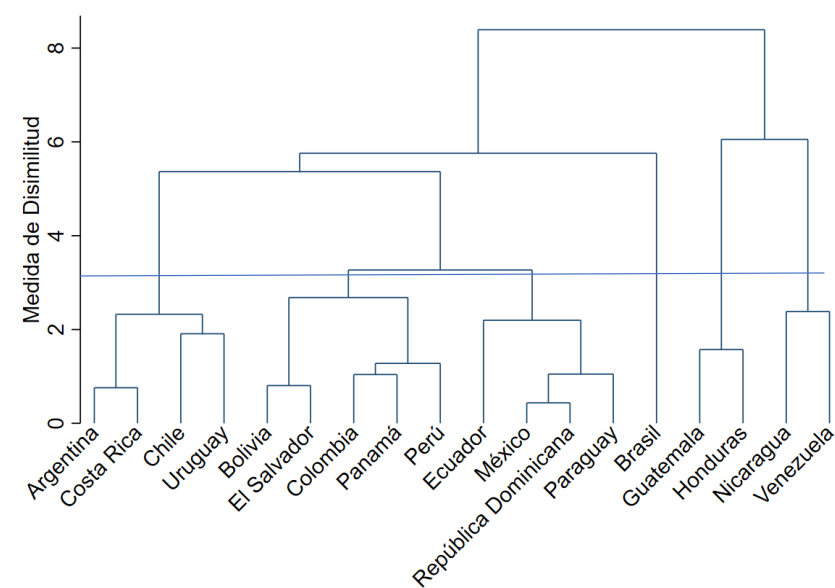

Nota: la lectura se realiza de abajo hacia arriba y en su interior aparecen líneas verticales y horizontales, utilizando estas últimas para indicar el punto de unión entre países. Así, la posición de la línea horizontal respecto a la medida de disimilitud de la parte izquierda indica la distancia donde se han realizado la unión de dos grupos, de modo que cuanto más hacia arriba se produzca una agrupación existirá más diferencia entre los casos, formando grupos más heterogéneos.

Fuente: elaboración propia. 
Las principales características de cada conglomerado quedan establecidas como sigue:

Primer conglomerado, conformado por Argentina, Costa Rica, Chile y Uruguay que poseen los mejores indicadores sanitarios de la región con un promedio de gasto público en salud de 5,3\% (\% PIB), un gasto per cápita en salud de USD 1794,33, una cantidad de camas hospitalarias cada mil habitantes de 1,83 , una tasa del $2 \%$ de mortalidad de COVID-19 y además cuenta con los mejores indicadores de corrupción y estabilidad política de la región.

El segundo está conformado únicamente por Brasil, que —a pesar de tener indicadores sanitarios, de estabilidad política y corrupción levemente por encima de la región — su indiferencia hacia la pandemia lo ha llevado a liderar el mayor número de contagios.

El tercer conglomerado está constituido por Bolivia, El Salvador, Colombia, Panamá y Perú. Se caracteriza por poseer — en general— favorables indicadores sanitarios, políticos y sociales, ligeramente por encima del promedio de toda la región

El cuarto conglomerado lo conforman Ecuador, México, República Dominicana y Paraguay. Cuenta con indicadores dentro del promedio de la región y se caracteriza principalmente por estar en la segunda ubicación en la cantidad de infectados y con la segunda tasa más alta de mortalidad por COVID-19.

El quinto, se constituye por Guatemala y Honduras y, que se caracterizan no solo por tener la menor cantidad de contagios y la menor cantidad de pruebas por millón de habitantes sino también por ser el conglomerado con inferiores indicadores sanitarios, sociales y políticos respecto al promedio de la región.

Finalmente, el sexto conglomerado está conformado por Nicaragua y Venezuela que se caracteriza principalmente por tener los peores indicadores políticos y sociales de la región. Pese a ello, aunque realizan la mayor cantidad de pruebas de COVID-19, tienen la tasa de mortalidad más alta de América Latina y el Caribe; de todos modos, la veracidad de sus datos oficiales está siendo fuertemente cuestionada. 
Peñafiel Chang: Panorama económico, político y sanitario de América Latina y el Caribe...

\section{Conclusiones}

Pese a la inevitable llegada del COVID-19 a la región, la clave — como se muestra en este artículo- para hacer frente a la pandemia en una primera instancia es limitar su expansión, con una oportuna gobernanza que genere certeza ciudadana mediante la protección social. Además, es fundamental contar con los medios competentes para fortificar el sistema sanitario. Sin embargo, como se evidencia, la región atraviesa un estancamiento económico, desafección popular y limitada infraestructura sanitaria que en su conjunto dificulta contener la velocidad de expansión del virus.

No obstante, las diferencias económicas y de estructura sanitarias en la región son producto de la heterogeneidad de las condiciones políticas, pero se distinguen características generales encontradas en América Latina y el Caribe, como poca inversión en salud, baja cantidad de pruebas de COVID-19 y limitada maniobra financiera.

Adicionalmente, este artículo demuestra que los países de la región que estuvieron mejor preparados para enfrentar el comienzo de la pandemia del COVID-19 son Uruguay, Costa Rica, Chile y Argentina, con un promedio de gasto público en salud como $\%$ PIB de 5,3\%, un gasto per cápita en salud de USD 1794,33, una cantidad de camas hospitalarias cada mil habitantes de 1,83 , una tasa del $2 \%$ de mortalidad de COVID-19 y los mejores indicadores de corrupción y estabilidad política de la región.

Lo sigue Brasil que — dada la indiferencia hacia la pandemia — lidera el número de infectados. Después, se encuentran Bolivia, El Salvador, Colombia, Panamá y Perú, seguidos por Ecuador, México, República Dominicana y Paraguay; estos últimos cuentan con indicadores dentro del promedio de la región, pero con alta cantidad de contagios y con la tasa de mortalidad por debajo de Brasil. Luego lo suceden Guatemala y Honduras, que se caracterizan no solo por tener la menor cantidad de contagios sino también por presentar inferiores indicadores sociales, políticos y sanitarios respecto al promedio de la región. Finalmente, Nicaragua y Venezuela son los países con las condiciones económicas, políticas y sanitarias más desfavorables de América Latina y el Caribe para enfrentar a la pandemia. 
Estos resultados no garantizan que los países que obtuvieron mejores condiciones económicas, políticas, sociales y sanitarias al inicio de la pandemia sean los mismos al final de esta, lo cual hace que sea de mucha importancia extender el estudio. De todos modos, resulta interesante no solo realizar comparaciones de resultados con distintos cortes en el tiempo sino también extender el análisis a otras regiones del mundo. Por último, es inevitable que los hallazgos estén condicionados al criterio técnico del profesional dado que las decisiones de este impactarán en el tipo de modelo, periodicidad y elección de variables a modelar. Pese a ello, el panorama de América Latina y el Caribe muestra los grandes retos que persistirán en la región más allá de la pandemia.

\section{Anexos}

Tabla A1. Análisis descriptivo de variables

\begin{tabular}{lcccc}
\hline Variable & Media & Desviación estándar & Mínimo & Máximo \\
\hline Var1 & 0,0395 & 0,0130 & 0,015 & 0,064 \\
Var2 & 0,0290 & 0,0096 & 0,017 & 0,05 \\
Var3 & 1049 & 625,18 & 141 & 2229 \\
Var4 & 73,388 & 6,146 & 55 & 80 \\
Var5 & 0,3411 & 0,1342 & 0,15 & 0,63 \\
Var6 & 2899,22 & 4489,12 & 7 & 18397 \\
Var7 & 1,35 & 0,6233 & 0,6 & 2,6 \\
Var8 & 0,0491 & 0,0420 & 0,006 & 0,2 \\
Var9 & 1911,66 & 2160,90 & 63 & 7143 \\
Var10 & 36,722 & 14,684 & 16 & 71 \\
Var11 & 53,411 & 8,970 & 30,1 & 70,5 \\
\hline
\end{tabular}

Nota: estadísticas descriptivas.

Fuente: elaboración propia. 
Peñafiel Chang: Panorama económico, político y sanitario de América Latina y el Caribe...

Tabla A2. Matriz de covarianzas entre componentes

\begin{tabular}{lccc}
\hline & Componente 1 & Componente 2 & Componente 3 \\
\hline Componente 1 & 4,8548 & & \\
Componente 2 & $-1,2 \mathrm{e}-08$ & 1,8397 & \\
Componente 3 & $2,3 \mathrm{e}-08$ & $-1,5 \mathrm{e}-08$ & 1,3161 \\
\hline
\end{tabular}

Nota: para las fuentes y las definiciones de los componentes ver las ecuaciones 25, 26 and 27.

Fuente: elaboración propia.

Tabla A3. Estimaciones de los tres primeros componentes para cada una de las observaciones

\begin{tabular}{lccc}
\hline País & Componente 1 & Componente 2 & Componente 3 \\
\hline Argentina & 2,2109 & $-0,858$ & $-0,362$ \\
Bolivia & $-0,059$ & $-0,949$ & $-1,060$ \\
Brasil & 1,223 & 3,214 & 2,263 \\
Chile & 3,063 & 0,651 & 0,014 \\
Colombia & 1,135 & $-0,8004$ & $-0,597$ \\
Costa Rica & 2,165 & $-1,225$ & $-1,023$ \\
Ecuador & 0,1072 & 1,325 & 1,0297 \\
El Salvador & $-0,700$ & $-0,913$ & $-0,299$ \\
Guatemala & $-3,188$ & 1,741 & $-2,123$ \\
Honduras & $-2,632$ & 1,170 & $-0,768$ \\
México & $-0,344$ & 0,520 & $-0,067$ \\
Nicaragua & $-2,332$ & $-1,979$ & 2,573 \\
Panamá & 1,251 & $-0,427$ & 0,365 \\
Paraguay & $-0,897$ & 0,652 & $-0,804$ \\
Perú & 0,078 & $-0,4396$ & 0,0209 \\
República Dominicana & $-0,309$ & 0,946 & 0,1266 \\
Uruguay & 4,201 & $-0,8733$ & $-0,1303$ \\
Venezuela & $-4,071$ & $-1,757$ & 0,957 \\
\hline
\end{tabular}

Nota: la columna uno representa las observaciones. La segunda, tercera y cuarta columna representan las estimaciones de los componentes para cada una de las observaciones. Cuanto mayor es el número, mejor puntuación tienen respecto al componente.

Fuente: elaboración propia. 
Tabla A4. Clúster encadenamiento completo para hallar la jerarquia de agrupación

\begin{tabular}{cc}
\hline Números de clúster & Calinski/Harabasz Pseudo-F \\
\hline 2 & 8,82 \\
3 & 7,90 \\
4 & 8,11 \\
5 & 15,11 \\
6 & 16,01 \\
7 & 16,18 \\
8 & 16,22 \\
9 & 18,86 \\
10 & 20,03 \\
11 & 23,34 \\
12 & 26,67 \\
13 & 29,97 \\
14 & 33,36 \\
15 & 41,20 \\
\hline
\end{tabular}

Notas: el índice Pseudo F se describe como: (Suma de cuadrados entre clústers/ (c-1)) / (suma de cuadrados dentro de cada clústers / (nc)) con c indicando el número de grupos y $\mathrm{n}$ indicando el número de observaciones, el cual mide la separación entre todos los grupos. Cuanto mayor es el número, más disperso está el grupo, menor es el número, más enfocado está el grupo.

Fuente: elaboración propia. 
Peñafiel Chang: Panorama económico, político y sanitario de América Latina y el Caribe...

Tabla A5. Estadisticas descriptivas de cada conglomerado según dendrograma con corte de disimilidad de 3

\begin{tabular}{lccccccccccc}
\hline & Var1 & Var2 & Var3 & Var4 & Var5 & Var6 & Var7 & Var8 & Var9 & Var10 & Var11 \\
\hline Congl 1 & 0,053 & 0,02 & 1794,33 & 74,33 & 0,23 & 2978 & 1,83 & 0,019 & 2148,67 & 56 & 60,37 \\
Congl 2 & 0,038 & 0,05 & 1472 & 79 & 0,27 & 18397 & 1,50 & 0,053 & 296 & 35 & 56 \\
Congl 3 & 0,041 & 0,02 & 912 & 75,20 & 0,26 & 2123 & 1,04 & 0,042 & 1679 & 34,80 & 55,70 \\
Congl 4 & 0,038 & 0,04 & 954 & 74 & 0,41 & 3577 & 1,37 & 0,050 & 719,33 & 31,67 & 53,27 \\
Congl 5 & 0,024 & 0,04 & 435 & 60 & 0,52 & 254 & 0,65 & 0,050 & 112,50 & 26 & 47,10 \\
Congl 6 & 0,030 & 0,02 & 323,50 & 73,50 & 0,48 & 89 & 0,85 & 0,127 & 6686,50 & 19 & 36,90 \\
\hline
\end{tabular}

Nota: el primer conglomerado está formado por Argentina, Costa Rica, Chile y Uruguay, el segundo conglomerado por Brasil, el tercer conglomerado por Bolivia, El Salvador, Colombia, Panamá y Perú, el cuarto conglomerado por Ecuador, México, República Dominicana y Paraguay, el quinto conglomerado por Guatemala y Honduras y el sexto conglomerado por Nicaragua y Venezuela. Siendo Var1: Gasto Público \%PIB, Var2: Gasto Privado \%PIB, Var3: Gasto per Cápita en Salud, Var4: Índice de cobertura de Salud, Var5: Gasto de Bolsillo como \% de gasto en Salud, Var6: casos confirmados al 10/04/20, Var7: camas disponibles cada 1,000 hbts, Var8: Tasa de Mortalidad, Var9: Test millón de Hbts, Var10: Índice de percepción de corrupción, Var11: Índice de riesgo Político.

Fuente: elaboración propia.

\section{Referencias}

Andersson, T., Schwaag-Serger, S., Sörvik, J., \& Wise, E. (2004). Cluster Policies Whitebook. IKED-International Organization for Knowledge Economy and Enterprise Development.

Arab-Mazar, Z., Sah, R., Rabaan, A. A., Dhama, K., \& Rodriguez-Morales, A. J. (2020). Mapping The Incidence of the COVID-19 Hotspot in Iran - Implications for Travellers. Travel Medicine and Infectious Disease, 34, 101630. https://doi.org/10.1016/j.tmaid.2020.101630

Banco Mundial (2020). La economía en los tiempos del Covid-19 (Informe semestral). https://openknowledge.worldbank.org/handle/10986/335 55 
Cadima, J., Cerdeira, J. O., \& Minhoto, M. (2004). Computational Aspects of Algorithms for Variable Selection in The Context of Principal Components. Computational Statistics \& Data Analysis, 47(2), 225-236. https://doi.org/10.1016/j.csda.2003.11.001

Cárdenas, O., Galindo, P., \& Vicente-Villadrón, J. L. (2007) Los métodos Biplot: evolución y aplicaciones. Revista Venezolana de Análisis de Coyuntura, XIII (1), 279-303. https://www.redalyc.org/pdf/364/ 36413113.pdf

Center for Systems Science and Engineering (CSSE) at Johns Hopkins University (JHU). (s. f.) COVID-19 Dashboard. Consultado el 10 de abril de 2020. https://www.arcgis.com/apps/opsdashboard/index.htm l\#/bda7594740fd40299423467b48e9ecf6

CEPAL (2019a) Balance Preliminar de las Economias de America Latina y el Caribe. https://repositorio.cepal.org/bitstream/handle/11362/45000/1 25/S1901097_es.pdf

CEPAL (2019b) Panorama Social de América Latina. CEPAL. https://www.ce pal.org/es/publicaciones/44969-panorama-social-america-latina-2019

CEPAL (2020a) América Latina y el Caribe ante la pandemia del COVID19: efectos económicos y sociales [Informe Especial COVID-19 No 1]. CEPAL. https://repositorio.cepal.org//handle/11362/45337

CEPAL (2020b) Dimensionar los efectos del COVID-19 para pensar en la reactivación [Informe Especial COVID-19 No 2]. CEPAL. https://ww w.cepal.org/es/publicaciones/45445-dimensionar-efectos-covid-19-pe nsar-la-reactivacion

Chen, C., Ibekwe-Sanjuan, F., \& Hou, J. (2010). The Structure and Dynamics of Co-Citation Clusters: A Multiple-Perspective Co-Citation Analysis. Journal of the American Society for Information Science and Technology, 61(7), 1386-1409. https://doi.org/10.1002/asi.21309

Dong, E., Du, H., \& Gardner, L. (2020). An interactive web-based dashboard to track COVID-19 in real time. The Lancet Infectious Diseases, 20(5), 533-534. https://doi.org/10.1016/s1473-3099(20)30120-1 
Peñafiel Chang: Panorama económico, político y sanitario de América Latina y el Caribe...

Fahmi, I. (2020) Coronavirus Disease 2019. https://pers.droneemprit.id/covi d19/

Gabriel, K. R. (1971). The Biplot Graphic Display of Matrices with Application to Principal Component Analysis. Biometrika, 3, 453-467. Available at: https://doi.org/10.2307/2334381

Gower, J. C. (1971). A General Coefficient of Similarity and Some of Its Properties. Biometrics, 27(4), 857. https://doi.org/10.2307/2528823

Hernández, R., Fernández, C., \& Baptista, M. (2010) Metodología de la investigación (quinta edición). Mc Grow Hill.

Hotelling, H. (1933) Analysis of a Complex of Statistical Variables into Principal Components, Journal of Educational Psychology, 24(6), 498520. https://doi.org/10.1037/h0071325

Ji, Y., Ma, Z., Peppelenbosch, M. P., \& Pan, Q. (2020). Potential association between COVID-19 mortality and health-care resource availability. The Lancet Global Health, 8(4), e480. https://doi.org/10.1016/s2214-109x (20)30068-1

Jollife, I. T. \& Cadima, J. (2016) Principal Component Analysis: A Review and Recent Developments. Philosophical Transactions of the Royal Society A: Mathematical, Physical and Engineering Sciences, 374(2065). https: //doi.org/10.1098/rsta.2015.0202

Kaiser, H. F. (1960). The Application of Electronic Computers to Factor Analysis. Educational and Psychological Measurement, 20(1), 141-151. https://doi.org/10.1177/001316446002000116

Lafuente, J. (2020, 18 de marzo). América Latina afronta la crisis del coronavirus entre tensiones políticas y fragilidad económica. El País. https://elpais.com/internacional/2020-03-17/america-latina-afr onta-la-crisis-del-coronavirus-entre-tensiones-politicas- $y$-fragilidad-ec onomica.html

Malamud, C. \& Núńez, R. (2020, 17 de marzo). El COVID-19 en América Latina: desafíos políticos, retos para los sistemas sanitarios e 
incertidumbre económica. Real instituto Elcano. http://www.realinstit utoelcano.org/wps/portal/rielcano_es/contenido?WCM_GLOBAL_C ONTEXT=/elcano/elcano_es/zonas_es/ari27-2020-malamud-nunez -covid-19-en-america-latina-desafios-politicos-retos-sistemas-sanitari os-e+incertidumbre-economica

Maldonado Valera, C., Martínez Pizarro, J., \& Jorge-Martínez, R. (2018) Protección social y migración. Una mirada desde las vulnerabilidades a lo largo del ciclo de la migración y de la vida de las personas. CEPAL. https://www.cepal.org/es/publicaciones/44021-proteccion-social-mig racion-mirada-vulnerabilidades-lo-largo-ciclo-la-migracion

Morales, V. \& Morales, B. (2019). Una técnica de agrupación robusta para un enfoque Big Data: Clarabd para tipos de datos mixtos. Perfiles, 2(22), 87-97. http://ceaa.espoch.edu.ec:8080/revista.perfiles/faces/Articulos/ Perfiles22Art12.pdf

Nuguer, V. \& Powell, A. (2020). Politicas para combatir la pandemia: Informe macroeconómico de América Latina y el Caribe 2020. Banco Interamericano de Desarrollo. https://publications.iadb.org/public ations/spanish/document/Informe_macroecon\%C3\%B3mico_de_A m\%C3\%A9rica_Latina_y_el_Caribe_2020_Pol\%C3\%ADticas_par a_combatir_la_pandemia.pdf

OIT (2019) Panorama Laboral 2019: América Latina y el Caribe. OIT. https: //www.ilo.org/wcmsp5/groups/public/---americas/---ro-lima/docume nts/publication/wcms_732198.pdf

Pan American Health Organization (PAHO) \& World Health Organization (WHO). (2020a). Epidemiological Update Novel coronavirus (COVID19). https://iris.paho.org/handle/10665.2/51909

Pan American Health Organization (PAHO) \& World Health Organization (WHO). (2020b). Reorganization and Progressive Expansion of Health Services for the Response to the COVID-19 Pandemic. https://iris.paho.or $\mathrm{g} / \mathrm{handle} / 10665.2 / 52215$ 
Peñafiel Chang: Panorama económico, político y sanitario de América Latina y el Caribe...

Pan American Health Organization (PAHO) \& World Health Organization (WHO). (2020c). Prehospital Emergency Medical Services: Readiness Checklist for Covid-19. https://iris.paho.org/handle/10665.2/52169

Pearson, K. (1901) On Lines and Planes of Closest Fit to Systems of Points in Space. Philosophical Magazine, 2, pp. 559-572. https://doi.org/10.1 080/14786440109462720

Peñafiel Chang, L., Camelli, G., \& Peñafiel Chang, P. (2020). Pandemia COVID-19: Situación política - económica y consecuencias sanitarias en América Latina. Ciencia Unemi, 13(35), 120-128. https://doi.org/ 10.29076/issn.2528-7737vol13iss33.2020pp120-128p

Peñafiel Chang, L. E. (2020). Dinámica de la tasa de interés, deflación y producción ante el shock del coronavirus en el marco de un modelo 'DSGE' neo-keynesiano para la economía ecuatoriana. X-pedientes económicos, 4(10), 6-18. https://ojs.supercias.gob.ec/index.php/X -pedientes_Economicos/article/view/119

Peñafiel Chang, L. E. (2021). Regionalización de la cadena de valor: oportunidades y desafíos para América Latina en la nueva era del SarsCov-2. Revista Ciencia UNEMI, 14(31), 81-91. https://doi.org/10.2 9076/issn.2528-7737vol14iss35.2021pp81-91p

Peters, S. (2020, 25 de marzo). La desigualdad mata: la pandemia del coronavirus en América Latina. Semana. https://www.semana.com /mundo/articulo/coronavirus-el-problema-de-la-desigualdad-en-ame rica-latina/659053/

Sanders, P. (2020, 14 de marzo). Latin America Announces Partial Lockdown as Coronavirus Spreads. BNN Bloomberg. https://www.bnnbloombe rg.ca/latin-america-announces-partial-lockdown-as-coronavirus-spre ads- 1.1405940

The Lancet Respiratory Medicine (2020) COVID-19: Delay, Mitigate, and Communicate. The Lancet Respiratory Medicine, 321. https://doi.org/ 10.1016/s2213-2600(20)30128-4 
Torres-Salinas, D., Robinson-García, N., Jiménez-Contreras, E., Herrera, F., \& López-Cózar, E. D. (2013). On the Use of Biplot Analysis for Multivariate Bibliometric and Scientific Indicators. Journal of the American Society for Information Science and Technology, 64(7), 14681479. https://doi.org/10.1002/asi.22837

Walker, P., Whittaker, C., Watson, O., Baguelin, M., Ainslie, K., Bhatia, S., Bhatt, S., Boonyasiri, A., Boyd, O., Cattarino, L., Cucunuba Perez, Z., Cuomo-Dannenburg, G., Dighe, A., Donnelly, C., Dorigatti, I., Van Elsland, S., Fitzjohn, R., Flaxman, S., Fu, H., ... Ghani, A. (2020). Report 12: The global impact of COVID-19 and strategies for mitigation and suppression. Imperial College London. https://doi.org/10.25561/7 7735

World Bank (2019) International Debt Statistics 2020. Washington, DC: World Bank. Doi: 10.1596/978-1-4648-146-7. License: Creative Commons Attribution CC BY 3.0 IGO

Wright, J., Ganesh A., Rao, S, Peng, Y., \& Ma, Y. (2009). Robust Principal Component Analysis: Exact Recovery of Corrupted LowRank Matrices via Convex Optimization. En Y. Benjio, D. Schuurmans, J. Lafferty, C. Williams \& A. Culotta (eds.) Advances in Neural Information Processing Systems 22 (pp. 2080-2088). NIPS.

Xu, B., Kraemer, M. U. G., Xu, B., Gutierrez, B., Mekaru, S., Sewalk, K., Loskill, A., Wang, L., Cohn, E., Hill, S., Zarebski, A., Li, S., Wu, C.H., Hulland, E., Morgan, J., Scarpino, S., Brownstein, J., Pybus, O., Pigott, D., \& Kraemer, M. (2020). Open access epidemiological data from the COVID-19 outbreak. The Lancet Infectious Diseases, 20(5), 534. https://doi.org/10.1016/s1473-3099(20)30119-5

Zhang, Y., Xu, J., Li, H., \& Cao, B. (2020). A Novel Coronavirus (COVID19) Outbreak. Chest, 157(4), e99-e101. https://doi.org/10.1016/j.ch est.2020.02.014 